\title{
A Study on the Control of BDS/GPS Self-phase Quadrifilar Helical Antenna for Ship
}

\author{
SUN Zhen, ZHAO Jiansen, WANG Shengzheng, XU Tie, LIU Wei and CHANG Yongmeng \\ Merchant Marine College, Shanghai Maritime University, Shanghai 201306, China
}

\begin{abstract}
A reconfigurable, self-phase quadrifilar helical antenna was designed at BDS/GPS frequency band. The impedance, gain and directivity of the antenna were studied by HFSS based on FEM (finite element method) and experiment. Results show the beam width of the main lobe of the pattern can reach over $160^{\circ}$ with the help of the load on the top of the antenna. And the power of the side-lobe level is very low. In addition, the quadrifilar helix antenna has excellent right-hand circular polarization performance with a beam width of $180^{\circ}$. Both single-frequency and double-frequency communications can be carried out by the antenna in the ranges between 1.2 and $1.8 \mathrm{GHz}$, with the bandwidth of each frequency about $60 \mathrm{MHz}$, the simulating and experimental results are nearly the same.
\end{abstract}

Key words: Quadrifilar helical antenna, controllability, beidou, FEM.

\section{Introduction}

With the improvement of marine BDS/GPS terminals [1, 2], the development of shipboard antenna has been promoted. Firstly, BDS/GPS system antennas require circular polarization, which possesses the advantage of anti-interference, anti-multipath or multipath multiplexing.

CP (circularly polarized) antennas can receive signals of various polarization modes, such as horizontal polarization, vertical polarization etc. When the incident wave is reflected by the reflector (such as a hull and the sea surface) and the incident angle is less than the Brester angle, the rotation of circularly polarized wave shows orthogonality, and a left-hand CP wave will be converted to a right-hand CP wave through reflection. Unlike land vehicles, ships are always in a non-stationary state during the voyage, which is especially severe in heavy weather. Through the simulation and experimental investigation, a self-phase BDS/GPS quadrifilar helical antenna [3-6] is designed, which provides reference for the

Corresponding author: ZHAO Jiansen, Ph.D., lecture, research fields: intelligent navigation, plasma antenna, gas discharge, AIS antenna, and GNSS antenna. compatibility of BDS and GPS and improves the accuracy of ship borne positioning systems.

\section{Models and Structure}

The antenna designed in this article does not require a feeding network, and the circular polarization of the antenna is realized only by the phase differences among the four helical arms. Fig. 1 shows the self-phase quadrifilar helical antenna designed by us.

The four helical arms are divided into two groups, each group has two adjacent helical arms, and the two arms are connected [7]. As shown in Fig. 1, arm 1 and arm 2 are in one group, and arm 3 and arm 4 are in the other group. Arms 1 and 3 are equal in length, while vibrators 2 and 4 are equal in length. The length of arms 1 and 2 varies by $1 / 4$ wavelengths. Arms 1 and 2 are connected with the inner conductor of the coaxial line, while arms 3 and 4 are connected with the outer conductor of the coaxial line $[8,9]$. Since the current directions of the inner and outer conductors are opposite, and the phase difference is $180^{\circ}$, hence, the phase difference between the two adjacent vibrators of the quadrifilar helix antenna is $90^{\circ}$.

As shown in Fig. 2, the reconfigurable BALUN can 


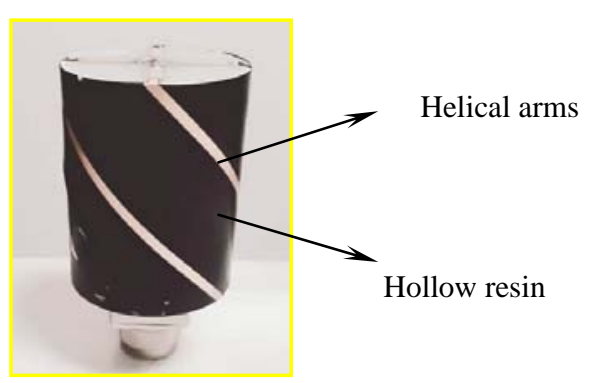

Fig. 1 The self-phase quadrifilar helical antenna.

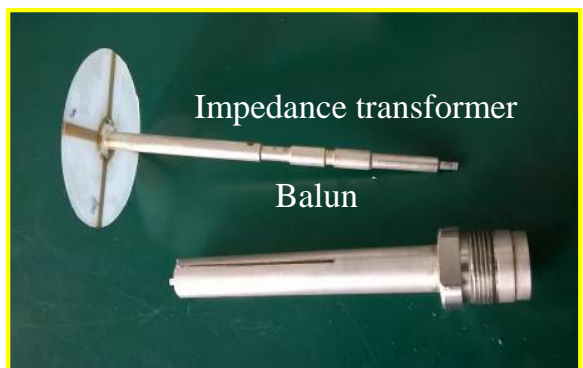

Fig. 2 Reconfigurable BALUN and antenna impedance transformer.

not only adjust the current balance between the inner and outer conductors of the coaxial line, but also can regulate the impedance and polarization bandwidth of the antenna by adjusting the movable ring on the adjustable BALUN. In addition, the power feeding strip on the antenna top serves as a top load, and the top load makes the main beam of the antenna pattern wider. The self-phase quadrifilar helical antenna is used for the purpose of reducing the antenna size because it does not require a matching network which makes the radial dimension larger. The adjustable BALUN of the antenna is arranged inside the hollow resin, and the movable ring on the adjustable BALUN center can be adjusted to change the frequency band and the circularly polarized characteristics of the antenna. Fig. 3 is the HFSS antenna model.

\section{Results and Analysis}

\subsection{Impedance Characteristics}

The dimensions of the quadrifilar helical antenna array are as follows: the quadrifilar helical antenna HFSS model adopts ideal boundary, with its axial length of $640 \mathrm{~mm}$; the length of the long helical vibrator is $812 \mathrm{~mm}$, the length of the short vibrator is
$726 \mathrm{~mm}$. The angle between the vibrator and the horizontal plane is $52^{\circ}$. The diameter of the antenna element is $20 \mathrm{~mm}$, and the width of the helical vibrator is $2 \mathrm{~mm}$.

The result of the antenna return loss test is shown in Fig. 4. It can be seen on the network analyzer screen that the values of S11 on the two frequency points, 1.22 and $1.57 \mathrm{GHz}$, both are less than $-15 \mathrm{~dB}$. Each frequency band has a bandwidth of about $60 \mathrm{MHz}$. The S11 at $1.22 \mathrm{GHz}$ is less than $-20 \mathrm{~dB}$, and it is close to $-20 \mathrm{~dB}$ at $1.57 \mathrm{GHz}$. Meanwhile, the distance between the movable ring on the adjustable BALUN and the top of the antenna is $22 \mathrm{~mm}$. It is obviously that the antenna is suitable for the Beidou Generation II and GPS band ranges. Based on the finite element method, HFSS is used to simulate the antenna array, and the simulation ranges from 1.0 to $2.0 \mathrm{GHz}$. It can be seen from the simulation value of the antenna shown in Fig. 5 that the antenna has dual frequency characteristics in the $1-2 \mathrm{GHz}$ band, which is close to the experimental results, and the center frequencies are $1.27 \mathrm{GHz}$ and $1.54 \mathrm{GHz}$ respectively.

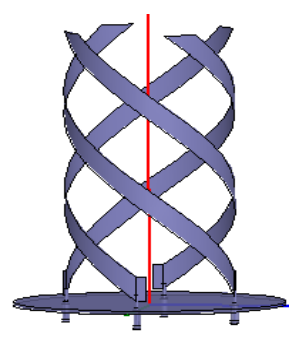

Fig. 3 Self-phase quadrifilar helical antenna model.

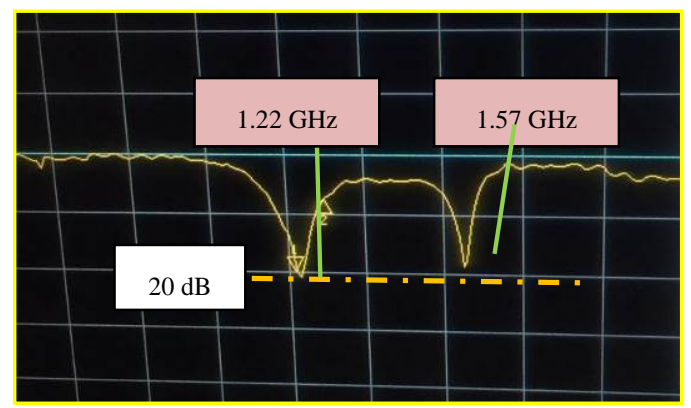

Fig. 4 Experimental results of antenna impedance characteristics. 


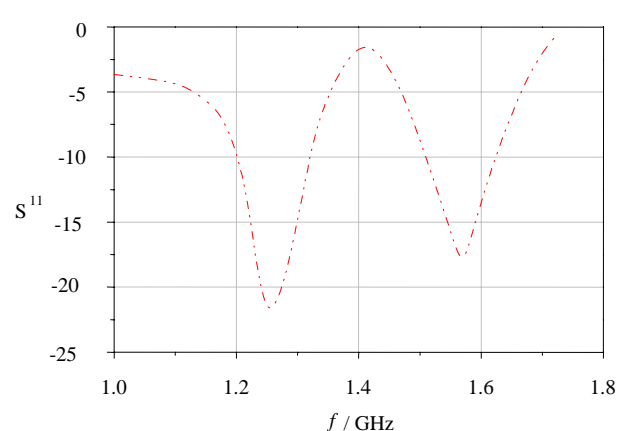

Fig. 5 Simulation results of antenna impedance characteristics.

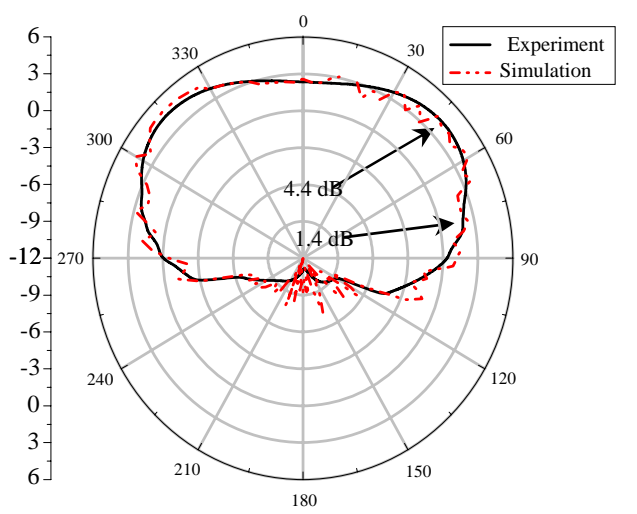

Fig. 6 Vertical directional diagram of the quadrifilar helical antenna.

\subsection{Directivity}

The radiation plot of the quadrifilar helical antenna is shown in Fig. 6, in which the maximum forward radiation of the antenna is $4.4 \mathrm{~dB}$, and the gain of the antenna is $1.4 \mathrm{~dB}$ at the elevation angle of $10^{\circ}$, and the HPBW (half power beam width) of the main lobe is about $160^{\circ}$. It can be seen that the beam width of the antenna is wider than that of the conventional quadrifilar antenna due to the top load of the quadrifilar helical antenna. Because of the top load, the maximum radiation direction is not pointed to the vertical direction, and the antenna gain of the vertical direction is about $2.3 \mathrm{~dB}$. In the elevation range of $50^{\circ}$, the highest antenna gain is about $4.4 \mathrm{~dB}$. Therefore, the antenna can cover the whole upper space, and when the tunable BALUN and antenna vibrator length are adjusted, the directivity of the antenna changes. In addition, the direction of the antenna could be changed when the top load is rotated, and therefore the dual circular polarizations could be regulated accordingly.

\section{Conclusions}

It is difficult for conventional microstrip antenna or quadrifilar helical antenna to realize the ultra wide beam width to meet the engine requirements. Even to increase the axial length of the quadrifilar helical antenna, the radiation pattern of the antenna tends to be close to that of the dipole, and the gain of the high-elevation angle will be greatly reduced. A reconfigurable, self-phase quadrifilar helical antenna is designed and introduced in this paper, it can realize antenna band frequency, gain and even polarization reconstruction through the adjustable BALUN and the rod type helical antenna. With the disturbance of the top load on the current, it can enhance the low-elevation gain, and also maintain the high-elevation gain. The antenna can be used in the antenna BDS/GPS navigation system, and also be used as left-hand circularly polarized antenna for signal multiplexing.

\section{Acknowledgements}

The research is supported by Shanghai Shuguang Plan Project (No: 15SG44) and NSFC of China (No: 51579143, 51379121 and 61304230) and China Postdoctoral Science Foundation (No: 2015M581585).

\section{References}

[1] LI, M., QU, L. Z., ZHAO, Q. L., GUO, J., SU, X., and LI, X. T. 2014. "Precise Point Positioning with the Beidou Navigation Satellite System.” Sensors 14: 927-43.

[2] Wang, X. Y., and Yang, G. M. 2014. "Dual Frequency and Dual Circular Polarization Slot Antenna for Beidou Navigation Satellite System Applications.” Micro. Opt. Technol. Lett. 56 (10): 2222-5.

[3] Kilgus, C. C. 1970. "Resonant Quadrifilar Helix Design.” Microwave Journal (18): 49-54.

[4] CHU, Q. X., LIN, W., LIN, W. X., and PAN, Z. K. 2013. “Assembled Dual-band Broadband Quadrifilar Helix 
Antennas with Compacted Power Divider Networks for CNSS Application.” IEEE Transaction on Antennas and Propagation 261 (2): 516-23.

[5] Takacs, A., Aubert, H., Belot, D., and Diez, H. 2013. "Miniaturisation of Quadrifilar Helical Antenna: Impact on Efficiency and Phase Centre Position.” IET Microw. Antenna Propag. 7 (3): 202-7.

[6] Masoud, Q. A., Amin, M., and Ali, S. W. 2015. "Self-phasing of Quadrifilar Helix Antenna by Relative Axial Displacement of Bifilars.” Microwave and Optical Technology Letters 57 (2): 430-2.

[7] Fartookzadeh, M., and Mohseni Armaki, S. H. 2016.
"Multi-band Conical and Inverted Conical Printed Quadrifilar Helical Antennas with Compact Feed Networks.” Int. J. Electron. Commun. 70 (1): 33-9.

[8] Khajepour, S., Ghaffarian, M S., and Moradi, G. 2017. "Design of Novel Multiband Folded Printed Quadrifilar Helical Sntenna for GPS/WLAN Applications.” IET Journals \& Magazines 53 (2): 58-60.

[9] HUANG, X., and PAN, J. 2016. "Design of the Top-loaded Quadrifilar Helix Antenna for Low Profile Applications.” In Proceedings of the 11th the International Symposium on Antennas, Propagation and EM Theory (ISAPE), 25-7. 